\title{
Blocking circ-CNST suppresses malignant behaviors of osteosarcoma cells and inhibits glycolysis through circ-CNST-miR- 578-LDHA/PDK1 ceRNA networks
}

Rui Hu${ }^{1+}$, Shan $\mathrm{Chen}^{2+}$ and Jianxin $\mathrm{Yan}^{3^{*}}$

\begin{abstract}
Background: CircRNA CNST (circ-CNST) is a newly identified biomarker for prognosis of osteosarcoma (OS). However, its role in OS progression remains to be well documented.

Methods: Expression of circ-CNST, microRNA (miR)-578, lactate dehydrogenase A (LDHA), and pyruvate dehydrogenase kinase 1 (PDK1) was detected by quantitative real-time polymerase chain reaction and Western blotting. The physical interaction was confirmed by dual-luciferase reporter assay. Cell behaviors and glycolysis were measured by 3-(4,5-dimethylthiazolyl-2)-2,5-diphenyltetrazolium bromide assay, colony formation assay, flow cytometry, transwell assays, xenograft experiment, and commercial kits.

Results: Circ-CNST was upregulated in human OS tissues and cells, accompanied with downregulation of miR-578 and upregulation of LDHA and PDK1. There were negative correlations between miR-578 expression and circ-CNST or LDHA/PDK1 in OS tissues. Moreover, high circ-CNST/LDHA/PDK1 or low miR-578 might predict shorter overall survival, advanced TNM stages, and lymph node metastasis. Physically, miR-578 was targeted by circ-CNST, and miR578 could target LDHA/PDK1. Functionally, blocking circ-CNST and restoring miR-578 enhanced apoptosis rate and suppressed cell proliferation, colony formation, migration, and invasion in 143B and U2OS cells, accompanied with decreased glucose consumption, lactate production, and adenosine triphosphate (ATP)/adenosine diphosphate (ADP) ratio. Furthermore, in vivo growth of U2OS cells was retarded by silencing circ-CNST. Depletion of miR-578 could counteract the suppressive role of circ-CNST deficiency in 143B and U2OS cells, and restoring LDHA or PDK1 partially reversed the role of miR-578 inhibition as well.
\end{abstract}

Conclusion: Circ-CNST knockdown could antagonize malignant behaviors and glycolysis of OS cells by regulating miR-578-LDHA/PDK1 axes.

Keywords: Circ-CNST, miR-578, Osteosarcoma, Glycolysis, LDHA, PDK1

\footnotetext{
*Correspondence: yjx7401@163.com

${ }^{\dagger}$ Rui Hu and Shan Chen are co-first authors.

${ }^{3}$ Department of Joint Surgery, The Central Hospital of Enshi Tujia and Miao

Autonomous Prefecture, No. 158 Wuyang Avenue, Enshi City 445000, Hubei Province, China

Full list of author information is available at the end of the article
}

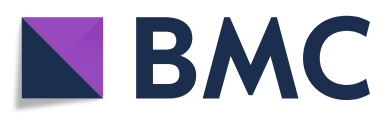

(- The Author(s). 2021 Open Access This article is licensed under a Creative Commons Attribution 4.0 International License, which permits use, sharing, adaptation, distribution and reproduction in any medium or format, as long as you give appropriate credit to the original author(s) and the source, provide a link to the Creative Commons licence, and indicate if changes were made. The images or other third party material in this article are included in the article's Creative Commons licence, unless indicated otherwise in a credit line to the material. If material is not included in the article's Creative Commons licence and your intended use is not permitted by statutory regulation or exceeds the permitted use, you will need to obtain permission directly from the copyright holder. To view a copy of this licence, visit http://creativecommons.org/licenses/by/4.0/. The Creative Commons Public Domain Dedication waiver (http://creativecommons.org/publicdomain/zero/1.0/) applies to the data made available in this article, unless otherwise stated in a credit line to the data. 


\section{Introduction}

Osteosarcoma (OS), arising from transformed mesenchymal cells, is the most frequent primary bone tumor ranging from children to adolescents and young adults [1]. Metabolic reprogramming in cancer is manifested by persistent aerobic glycolysis and suppression of mitochondrial function, which is called the Warburg effect, a hallmark of many malignant tumors including OS [2]. Although the generation of adenosine triphosphate (ATP) is less efficient, tumor cells benefit from aerobic glycolysis in growth, metastasis, and drug resistance [3, 4]. Lactate is an energy source and L-lactate shuttles from OS cells to neighboring cells, mediating tumor microenvironment [5, 6]. Although treatment for OS has been improved, the likelihood of survival remains low for OS patients with metastasis and recurrence. Moreover, pulmonary metastasis is observed in $30-35 \%$ of OS patients after initial treatment for 2 to 3 years [7]. It is necessary to understand the molecular mechanism of OS progression and glycolysis to identify more effective therapeutic targets.

Very recently, emerging roles of noncoding RNAs have been identified in the pathogenesis, diagnosis, and prognosis of OS [8]. Circular RNAs (circRNAs) are generally novel endogenous noncoding RNAs with covalently closed-loop structure, and deregulation of circRNAs has been demonstrated in OS patients by Gene Expression Omnibus (GEO) database. The regulatory functions of circRNAs result in OS cell progression or restraint [9]. Moreover, circRNAs are attractive new class of potential biomarkers and therapeutic targets for OS [10, 11]. CircRNA CNST (circ-CNST, hsa_circ_0017311) is upregulated in OS patients and represents an independent biomarker for poor prognosis [12]. However, the function and mechanism of circ-CNST in OS progression remains largely unclear, since it has only recently identified in OS.

In this study, we attempted to investigate the role of circ-CNST dysregulation in malignant behaviors of OS cells and glycolysis. Lactate dehydrogenase A (LDHA) and pyruvate dehydrogenase kinase 1 (PDK1) are key players involved in anaerobic glycolysis and tumor progression $[13,14]$. Strikingly, LDHA and PDK1 are emerging anti-OS therapeutic targets $[15,16]$. Severing as microRNAs (miRNAs) sponge is one of biological functions of circRNAs in various tumors including OS [10, 17]. Furthermore, circRNA-based competing endogenous RNA (ceRNA) networks have been constructed in OS based on circRNA-miRNA pairs and miRNAmessenger RNA (mRNA) pairs $[18,19]$. Thus, we aimed to further confirm whether miRNA (miR)-578, a poorly understood miRNA yet, was a target of circ-CNST in regulating LDHA and PDK1.

\section{Materials and methods}

OS patients and tissue samples

Carcinoma tissues and corresponding adjacent noncarcinoma tissues were obtained from 29 patients with primary OS during the operation. All specimens were diagnosed as OS by clinical, imaging, and histological examinations, and patients received anti-tumor treatment before this study were excluded. Clinicopathologic features of these patients were summarized in Table 1. This study was ratified by the Medical Ethics Committee of the Central Hospital of Enshi Tujia and Miao Autonomous Prefecture, and informed consent was provided form each patient or his guardian.

\section{Cells and cell culture}

Human fetal osteoblasts (hFOB1.19; \#60357) and human OS cell lines including HOS (\#CRL-1543), MG63 (\#CRL-1427), 143B (\#CRL-8303), and U2OS (\#HTB-96) were purchased from BCRC (Taiwan, China) and ATCC (Manassas, VA, USA). The hFOB1.19 cells were cultured in Dulbecco's modified Eagle's medium (DMEM)/F12 (R\&D systems, Minneapolis, MN, USA) at $34{ }^{\circ} \mathrm{C}$, and OS cells were cultivated in DMEM (R\&D systems) at 37 ${ }^{\circ} \mathrm{C}$. All cells were incubated in medium supplemented with $10 \%$ fetal bovine serum with $5 \% \mathrm{CO}_{2}$.

Table 1 Relationship between circ-CNST expression and clinicopathologic features of osteosarcoma patients

\begin{tabular}{|c|c|c|c|c|}
\hline & \multirow{2}{*}{$\begin{array}{l}\text { Characteristics, } \\
n=29\end{array}$} & \multicolumn{2}{|c|}{ circ-CNST expression } & \multirow{2}{*}{$\begin{array}{l}P \\
\text { value }^{a}\end{array}$} \\
\hline & & Low $(n=14)$ & High $(n=15)$ & \\
\hline \multicolumn{5}{|l|}{ Gender } \\
\hline Female & 17 & 9 & 8 & \multirow[t]{2}{*}{0.7104} \\
\hline Male & 12 & 5 & 7 & \\
\hline \multicolumn{5}{|l|}{ Age (years) } \\
\hline$\leq 60$ & 15 & 9 & 6 & \multirow[t]{2}{*}{0.2723} \\
\hline$>60$ & 14 & 5 & 9 & \\
\hline \multicolumn{5}{|l|}{ TNM grade } \\
\hline $\mid+\|$ & 12 & 9 & 3 & \multirow[t]{2}{*}{$0.0253^{*}$} \\
\hline$I I I+I V$ & 17 & 5 & 12 & \\
\hline \multicolumn{5}{|c|}{ Lymph node metastasis } \\
\hline Positive & 18 & 5 & 13 & \multirow[t]{2}{*}{$0.0078^{*}$} \\
\hline Negative & 11 & 9 & 2 & \\
\hline \multicolumn{5}{|l|}{ Tumor size } \\
\hline$\leq 5 \mathrm{~cm}$ & 11 & 10 & 1 & \multirow[t]{2}{*}{$0.0016^{*}$} \\
\hline$>5 \mathrm{~cm}$ & 18 & 4 & 14 & \\
\hline
\end{tabular}

TNM, tumor-node-metastasis

${ }^{*} P<0.05$

${ }^{\mathrm{a} C h i}$-square test 
Ribonuclease $\mathrm{R}$ (RNase $\mathrm{R}$ ) treatment and quantitative realtime polymerase chain reaction (RT-qPCR)

Cultured cells and tissues were subjected to RNeasy kit (Invitrogen, Carlsbad, CA, USA) following the manufacturer's instructions to extract total RNA, which was used to synthesize complementary DNA (cDNA) with Reverse Transcription System (Promega, Madison, WI, USA). For RNase R treatment, total RNA $(2 \mu \mathrm{g})$ from 143B and U2OS cells was incubated with $5 \mathrm{U}$ RNase R (Solarbio, Beijing, China) for $30 \mathrm{~min}$ at $37{ }^{\circ} \mathrm{C}$. The expression levels of circ-CNST, linear CNST, miR-578, LDHA, and PDK1 were quantified with GoTaq ${ }^{\bullet}$ qPCR and RT-qPCR systems (Promega) and normalized to $\beta$-actin and U6 mRNA levels. The primers were summarized in Table 2 . The relative expression was calculated using the $2^{-\Delta \Delta \mathrm{Ct}}$ method.

\section{Cell transfection}

Cell transfection of exogenous nucleotides into 143B and U2OS cells was performed with Lipofectamine 3000 reagent (Invitrogen) following the manufacturer's instructions. Small interference RNA (siRNA) targeting circ-CNST (si-circ-CNST) and its negative control si$\mathrm{NC}$, short hairpin RNA (shRNA) targeting circ-CNST (sh-circ-CNST) and sh-NC, miR-578 mimic and miR-
NC mimic, and miR-578 inhibitor (anti-miR-578) and anti-miR-NC were synthesized by GENEWIZ (Beijing, China). The sequences were presented in Table 2. The shRNAs were inserted into pSilencer 4.1-CMV puro vector (EK-Bioscience, Shanghai, China), and stably shRNA-transfected cells were selected by Puromycin. Overexpression vectors of circ-CNST, LDHA, and PDK1 were constructed depending on pCD5-ciR (Geneseed, Guangzhou, China) and pcDNA3.1 (+) (EK-Bioscience). The transiently transfected cells were collected after transfection for $24 \mathrm{~h}$.

\section{3-(4,5-dimethylthiazolyl-2)-2,5-diphenyltetrazolium bromide (MTT) assay and colony formation assay}

For MTT assay, transfected cells $143 \mathrm{~B}$ and U2OS cells were re-seeded in 96-well plate at a density of $2 \times 10^{4}$ cells per well, and each group was set with 6 parallel wells. The cells were cultured with complete medium for another $24 \mathrm{~h}, 48 \mathrm{~h}$, and $72 \mathrm{~h}$, and subjected to MTT Cell Proliferation and Cytotoxicity Assay Kit (Beyotime, Shanghai, China) according to the directions for use. The colorimetric analysis was measured at $570 \mathrm{~nm}$ on Multiskan Ascent 354 microplate reader (Abcam, Cambridge, MA, USA).

Table 2 The primers and siRNAs used in this study

\begin{tabular}{|c|c|}
\hline Name & Sequence \\
\hline \multirow[t]{2}{*}{ circ-CNST (152 nt) } & 5'-TGTGCAACCACATACAGTTACG-3' (forward) \\
\hline & 5'-CAGCATATGTGACTGC-3' (reverse) \\
\hline \multirow[t]{2}{*}{ linear CNST (165 nt) } & 5'-TCCCCTTTGCCTTCATCAGA-3' (forward) \\
\hline & 5'-TGTGGTTGCACAGTTTTCCA-3' (reverse) \\
\hline \multirow[t]{2}{*}{ miR-578 } & 5'-GTGCAGGGTGTTAGGA-3' (forward) \\
\hline & 5'-GAAGAACACGTCTGGT-3' (reverse) \\
\hline \multirow[t]{2}{*}{ LDHA (165 nt) } & 5'-CAGGTGGTTGAGAGGGTCTा-3' (forward) \\
\hline & 5'-CTTCAAACGGGCCTCTTCCT-3' (reverse) \\
\hline \multirow[t]{2}{*}{ PDK1 } & 5'-GCTTCGATGCAGCAACAACA-3' (forward) \\
\hline & 5'-AGGCGCTGCTITAAGCTCTG-3' (reverse) \\
\hline \multirow[t]{2}{*}{$\beta$-actin } & 5'-ACACCTTCTACAATGAGCTG-3' (forward) \\
\hline & 5'-CTGCTTGCTGATCCACATCT-3' (reverse) \\
\hline \multirow[t]{2}{*}{ U6 } & 5'-CTCGCTTCGGCAGCACAT-3' (forward) \\
\hline & 5'-AACGCTTCACGAATTTGCGT-3' (reverse) \\
\hline \multirow[t]{2}{*}{ si(sh)-circ-CNST } & 5'-GTCTCTTGATGTGTTGCACAA-3' (sense) \\
\hline & 5'-GTGCAACACATCAAGAGACTT-3' (anti-sense) \\
\hline \multirow[t]{2}{*}{ si (sh)-NC } & 5'-TCTGGTTGACATCATGCTTAATGTG-3' (sense) \\
\hline & 5'-CATTAAGCATGATGTCAACCAGACA-3' (anti-sense) \\
\hline miR-578 mimic & 5'-CUUCUUGUGCUCUAGGAUUGU-3' \\
\hline miR-NC & 5'-GGUUCGUACGUACACUGUUCA-3' \\
\hline anti-miR-578 & 5'-ACAATCCTAGAGCACAAGAAG-3' \\
\hline anti-miR-NC & 5'-UGAACAGUGUACGUACGAACC-3' \\
\hline
\end{tabular}


For colony formation assay, 143B and U2OS cells were re-seeded in 6-well plate after transfection for $24 \mathrm{~h}$ at a density of 200 cells per well. Three parallel wells were set up in each transfection group. The cells were cultured in complete medium for 14 days. The colonized spots were stained with $0.25 \%$ crystal violet solution (Beyotime). The colonies were observed under a microscope, and colony number was counted.

\section{Flow cytometry (FCM)}

Annexin V-fluorescein isothiocyanate (FITC) apoptosis detection kit (Beyotime) and FCM were performed to measure apoptosis rate of 143B and U2OS cells with different transfection. A total of $5 \times 10^{4}$ cells were harvested and re-suspended in Annexin V-FITC binding buffer. Then, $5 \mu \mathrm{L}$ of Annexin-FITC and $10 \mu \mathrm{L}$ of propidium iodide (PI) were added in sequence and kept away from light for $15 \mathrm{~min}$. Stained cells were examined on FACS Calibur flow cytometer(BD Biosciences, San Jose, CA, USA) and analyzed on FACS Diva (BD Biosciences).

\section{Transwell assays}

Cell migration and invasion were tested by transwell insert (6.4-mm diameter and $8-\mu \mathrm{m}$ pore size) purchased from BD Biosciences. For migration assay, the lower chamber was added with complete medium, and the upper insert was added with $5 \times 10^{4}$ cells in serum-free medium. Cells in transwell system were cultured for another $48 \mathrm{~h}$, and then subjected to crystal violet $(0.25 \%)$ staining. Stained cells were observed under a microscope ( $\times 100)$, and migratory cell number was counted. For invasion assay, the insert was coated with Matrigel membrane (BD Biosciences), and $5 \times 10^{5}$ transfected cells were used.

\section{Determination of glucose, lactate, and ATP levels}

Glucose Uptake Assay Kit (Colorimetric), L-Lactate assay Kit (Colorimetric), and adenosine diphosphate (ADP)/ATP Ratio Assay Kit (Bioluminescent) were provided from Abcam (Cambridge, UK). All experiments were conducted in accordance with the manuals, respectively.

\section{Xenograft tumor models}

All animal experiments were reviewed and approved by the Institutional Animal Care and Use Committee of the Central Hospital of Enshi Tujia and Miao Autonomous Prefecture. A sum of 16 female ALB/c nude mice (4week-old) were purchased and maintained under pathogen-free conditions. Serum-free cell suspensions of stably transfected U2OS cells were injected subcutaneously into the posterior flanks of nude mice at a density of $5 \times 10^{6}$ cells per mice, and the mice were randomly divided into two groups $(n=8)$ : sh-NC and sh-circ-
CNST. Caliper was used to measure tumor dimensions every 3 days after 7-day inoculation, and volume was calculated according to $0.5 \times$ length $\times$ width $^{2}$ formula. At the termination of the experiment, mice were sacrificed and tumors were excised. Xenograft tumors were weighted with electronic scales and photographed with a camera. Tumor tissues were stored in liquid nitrogen for further RNA isolation. All animal experiments were performed following the Guide for the Care and Use of Laboratory Animals (GB/T 35892-2018; Standardization Administration of the People Republic of China).

\section{Dual-luciferase reporter assay}

Circinteractome (https://circinteractome/circular_rna_ query=hsa_circ_0017311\&mirna) and Targetscan (http:// www.targetscan/vert_71/=hsa-miR-578) databases were utilized to predict miR-578-binding sites in circ-CNST, LDHA, and PDK1. To test the abovementioned target relationships, dual-luciferase reporter assays were carried out. The wild-type (WT) sequences (with a specific binding site for miR-578) of circ-CNST, LDHA 3'UTR, and PDK1 3'UTR were respectively cloned into luciferase reporter vector pMIR-REPORT (Promega, containing Firefly), as well as the mutated (MUT) sequences (with mutations of miR-578-binding sites). 143B and U2OS cells were co-transfected with WT/MUT vectors, pRL-SV40 (internal control vector, containing Renilla), and miR-578 mimic or miR-NC mimic. After transfection for $24 \mathrm{~h}$, cell lysate was collected and luciferase activities of Firefly and Renilla were measured by the DualLuciferase Reporter Assay Kit (Promega) on GloMax Discover Microplate Reader (Promega).

\section{Western blotting}

Total protein in cultured cells was extracted by RIPA Lysis Buffer (Beyotime), and protein concentration was measured using BCA Protein Assay Kit (Beyotime). Proteins were denatured in loading buffer by boiling at 100 ${ }^{\circ} \mathrm{C}$ for $10 \mathrm{~min}$, and denatured protein samples were subjected to Western blotting assay [20]. The antibodies used were presented in Table 3. ECL ${ }^{\mathrm{mm}}$ Western blotting system (Merck, Darmstadt, Germany) was used to detect protein signals and densitometric quantification was performed using Image s software $(\mathrm{NIH}$, Bethesda, $\mathrm{MD}$, USA).

Table 3 The antibodies used in this study

\begin{tabular}{llll}
\hline Name & Cat. no. & Dilution ratio & Source \\
\hline LDHA & AF0216 & $1: 1000$ & Beyotime \\
PDK1 & AF7707 & $1: 1000$ & Beyotime \\
$\beta$-actin & AA128 & $1: 1000$ & Beyotime \\
HRP-labelled anti-Rabbit IgG & A0208 & $1: 1000$ & Beyotime \\
HRP-labelled anti-Mouse lgG & A0216 & $1: 1000$ & Beyotime \\
\hline
\end{tabular}




\section{Statistical analysis}

Statistical data were presented as means ( \pm standard deviation) from at least three independent experiments, and data analysis was further carried out using Student's $t$-test and/or one-way analysis of variance followed with Tukey's post hoc test. The statistical analysis was determined by GraphPad Prism 5.0 software (GraphPad, San Diego, CA, USA). Kaplan-Meier survival analysis determined overall survival of 29 OS patients with high/low expression of circ-CNST, miR-578, LDHA, and PDK1. A comparison with $P<0.05$ was deemed as statistically significant: asterisk represented $P<0.05$, double asterisks represented $P<0.01$, triple asterisks represented $P<$ 0.001 , and quadruple asterisk represented $P<0.0001$.

\section{Results}

Circ-CNST was an upregulated circRNA in OS patients and cells

Even though expression of circ-CNST in OS had once been identified, it was further validated in this present study. A set of OS patients were enrolled, and RT-qPCR data indicated that relative circ-CNST expression was increased in tumor tissues than adjacent normal tissues (Fig. 1a). Besides, high circ-CNST was found in OS tumors from patients with shorter overall survival, advanced TNM stages, and lymph node metastasis (Figure
S1A-S1C). Moreover, Chi-square test confirmed that circ-CNST level was significantly correlated with clinicopathologic features of OS patients, including TNM stage, lymph node metastasis, and tumor size (Table 1). In vitro, its level was higher in several OS cell lines, and 143B and U2OS cells exhibited the highest level of circCNST (Fig. 1b). The structure stability was examined by RNase R digestion. Linear CNST expression was significantly attenuated, but circ-CNST expression was little affected in RNase R-treated 143B and U2OS cells (Fig. $1 c, d)$. These results indicated that circ-CNST was a stably upregulated circRNA in OS and might predict heavy tumor burden and poor prognosis.

\section{Depleting circ-CNST antagonized malignant behaviors and glycolysis of OS cells}

Loss-of-function experiments were subsequently carried out to testify the role of circ-CNST in OS development. Special siRNA was utilized to knock down the abnormally high expression of circ-CNST in OS cells, and circ-CNST level was dramatically decreased in si-circCNST-transfected 143B and U2OS cells (Fig. 2a). Cell proliferation analyzed by MTT assay was inhibited by circ-CNST knockdown in transfected 143B and U2OS cells, as depicted by lower OD values (Fig. 2b, c); similarly, colony formation inhibition was observed in 143B

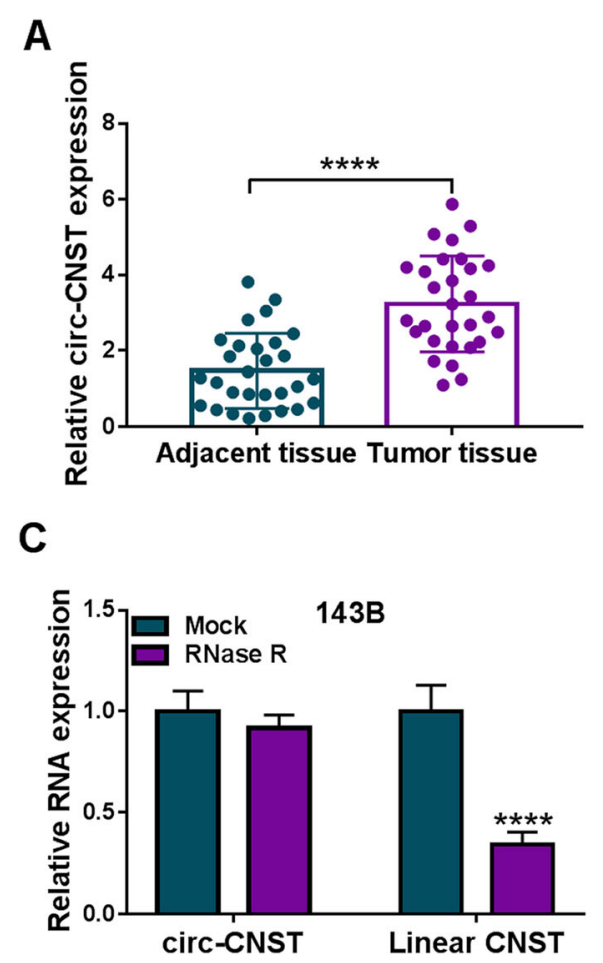

B
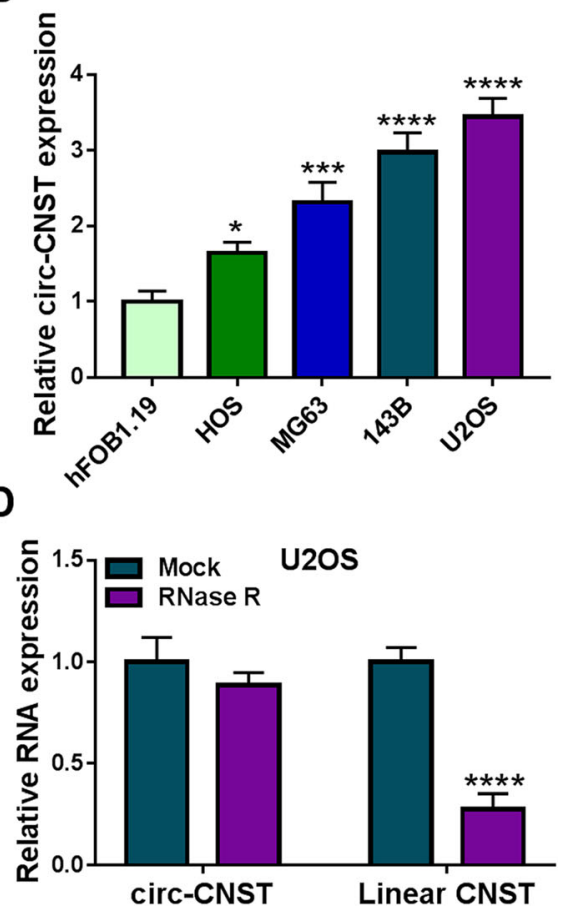

Fig. 1 Expression of circ-CNST in OS patients and cells. $\mathbf{a}, \mathbf{b}$ RT-qPCR measured relative circ-CNST expression in tumor tissues from OS patients ( $n$ = 29) comparing to adjacent normal tissues, and in human OS cell lines (HOS, MG63, 143B, and U2OS) comparing to hFOB1.19 cell line. c, d RTqPCR measured relative RNA expression of circ-CNST and linear CNST in 143B and U2OS cells treated with RNase R paralleled with mock-treated cells. ${ }^{*} P<0.05$, ${ }^{* *} P<0.001$, and ${ }^{* * *} P<0.0001$ 


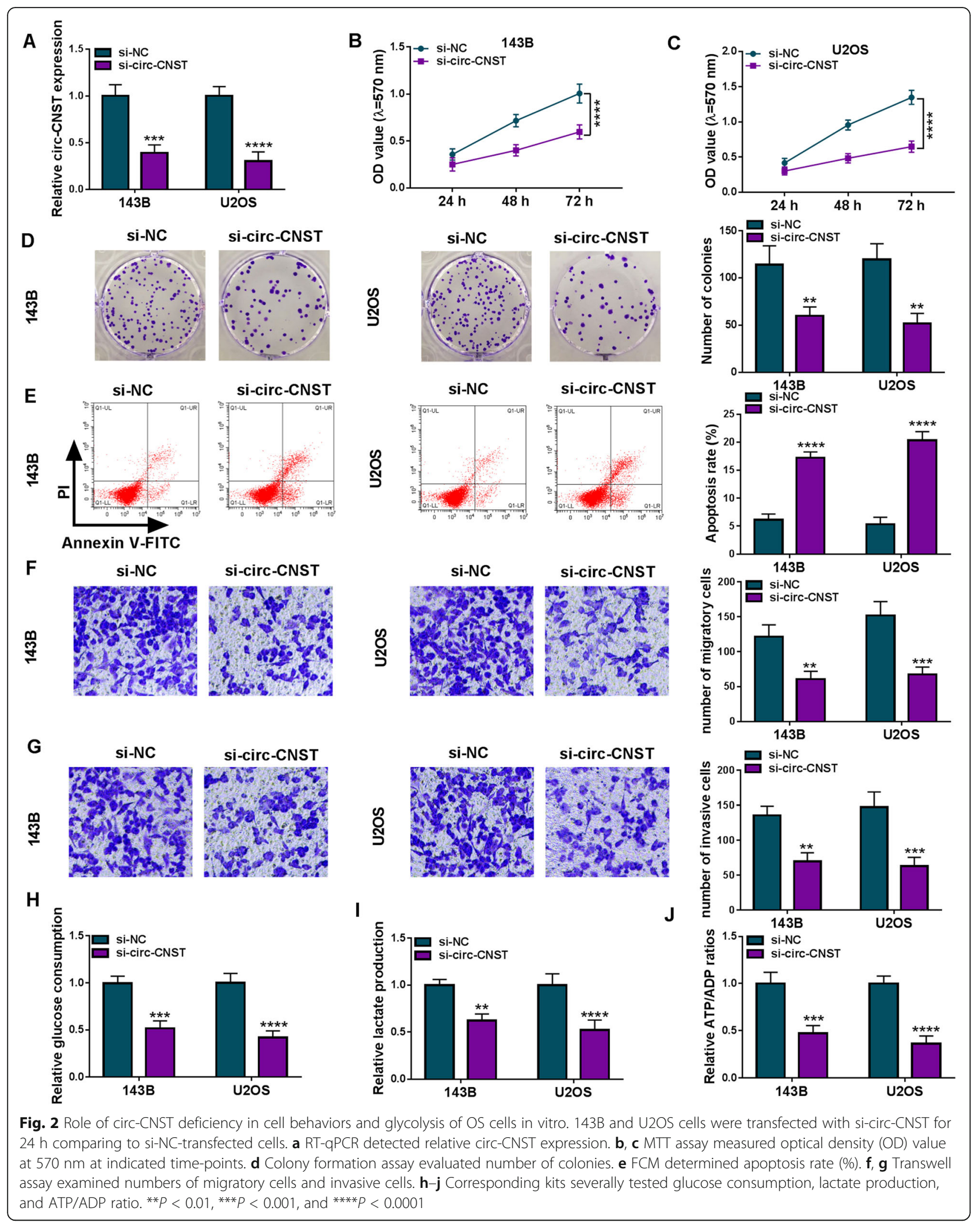


and $\mathrm{U} 2 \mathrm{OS}$ cells transfected with si-circ-CNST, as indicated by the declined number of colonies (Fig. 2d). On the contrary, apoptosis rate of $143 \mathrm{~B}$ and U2OS cells was elevated with si-circ-CNST transfection than si-NC transfection, suggesting a promoting role of circ-CNST knockdown in OS cell apoptosis. Transwell assays showed less migratory cells and invasive cells after transfection of si-circ-CNST versus si-NC in both $143 \mathrm{~B}$ and U2OS cells (Fig. 2f, g). Furthermore, commercial kits revealed an overall reduction of glucose consumption, lactate production, and ATP/ADP ratio in circ-CNSTdepleted 143B and U2OS cells (Fig. 2h-j). Collectively, these results demonstrated a tumor-suppressive role of circ-CNST knockdown in human OS cells in vitro by inhibiting malignant behaviors and glycolysis.

Thereafter, sh-circ-CNST was used to stably block circ-CNST expression in U2OS cells (Fig. 3a), as well as $143 \mathrm{~B}$ cells (Data were not showed). Comparing to 143B cells, U2OS cells showed higher circ-CNST level and higher transfection efficiency of sh-circCNST and thus stably transfected U2OS cells were injected into nude mice to induce xenograft tumors.
As a result, the volume and weight of xenograft tumors were restrained by blocking circ-CNST in advance (Fig. 3b, c), and lower circ-CNST level was detected in tumor tissues in sh-circ-CNST group (Fig. 3d). This result demonstrated a cell growth inhibition of circ-CNST deficiency in OS in vivo.

\section{Circ-CNST negatively modulated miR-578 in human OS cells via target binding}

The circinteractome database was selected to annotate miRNA targeting sites in circ-CNST, and miR-578 was predicted to be complementary to circ-CNST (Fig. 4a). MiR-578 mimic transfection led to overexpression of miR-578 in both $143 \mathrm{~B}$ and U2OS cells (Fig. 4b), which attenuated the luciferase activity of circ-CNST-WT vector and failed to affect luciferase activity of circ-CNST-MUT vector (Fig. 4c, d). This data validated the binding relationship between circCNST and miR-578. Expression of miR-578 was detected by RT-qPCR, and its level was lower in OS patients' tumor tissues and cells (Fig. 4e, g). Moreover, Pearson correlation coefficient analysis determined

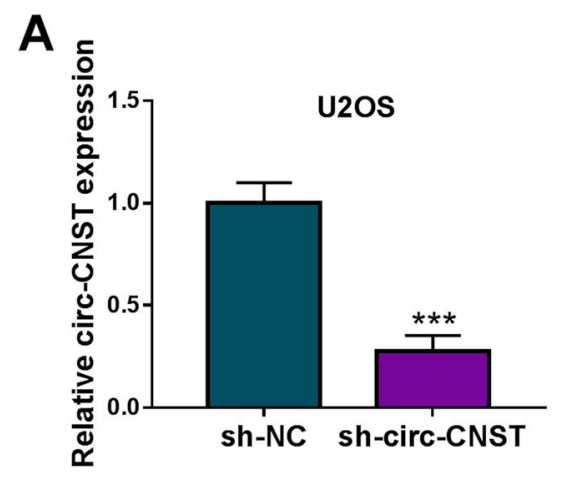

B
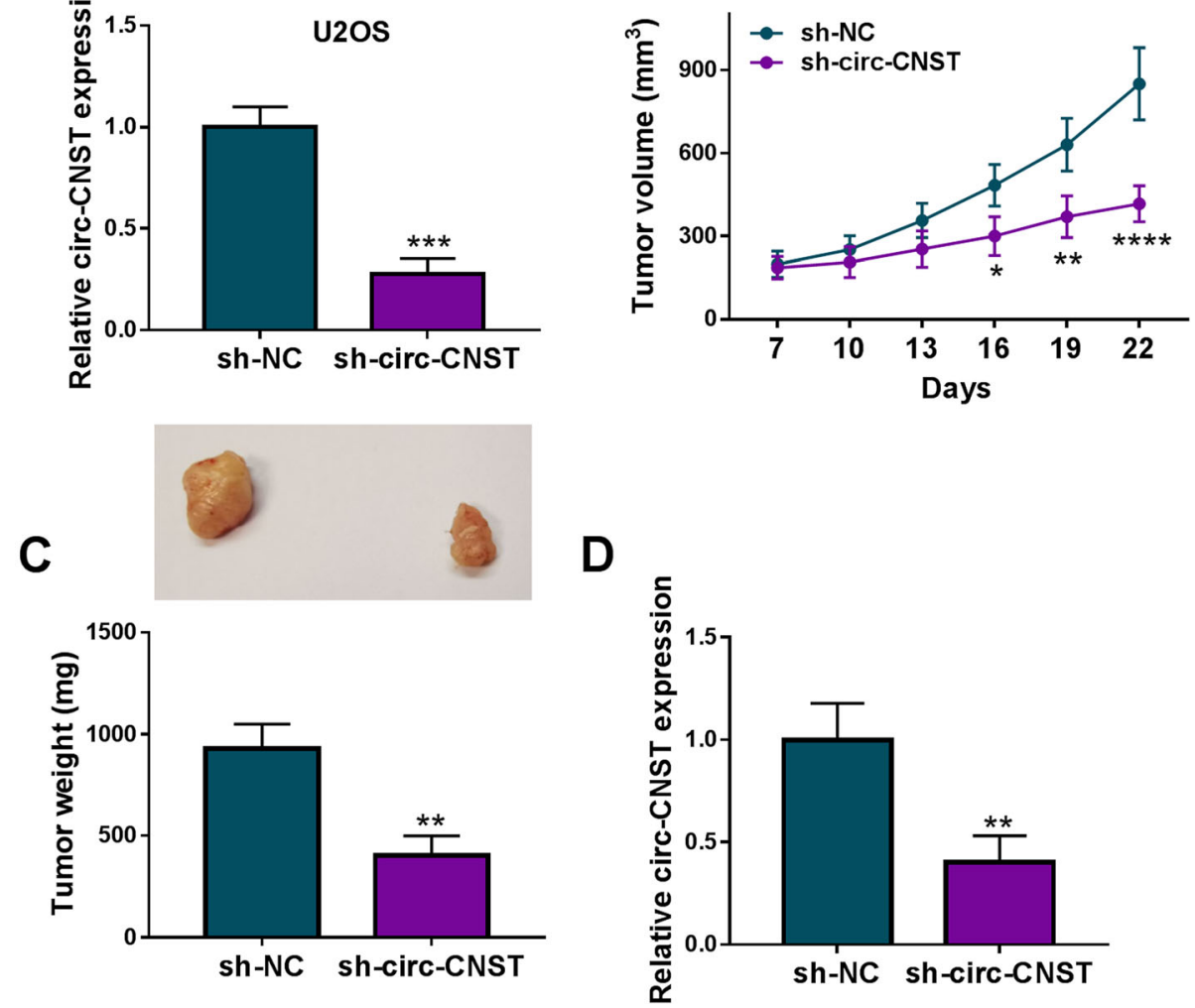

Fig. 3 Role of circ-CNST deficiency in cell growth of OS cells in vivo. a RT-qPCR detected relative circ-CNST expression in U2OS cells stably transfected with sh-circ-CNST comparing to sh-NC-transfected cells. b, c Transfected U2OS cells were inoculated in nude mice, and 8 mice were set in each group. b Tumor volume was calculated at indicated time-points. c Tumor weight was measured on the last day. $\mathbf{d}$ RT-qPCR detected relative circ-CNST expression in tissues from xenograft tumors. ${ }^{*} P<0.05,{ }^{* *} P<0.01$, ${ }^{* * *} P<0.001$, and ${ }^{* * *} P<0.0001$ 

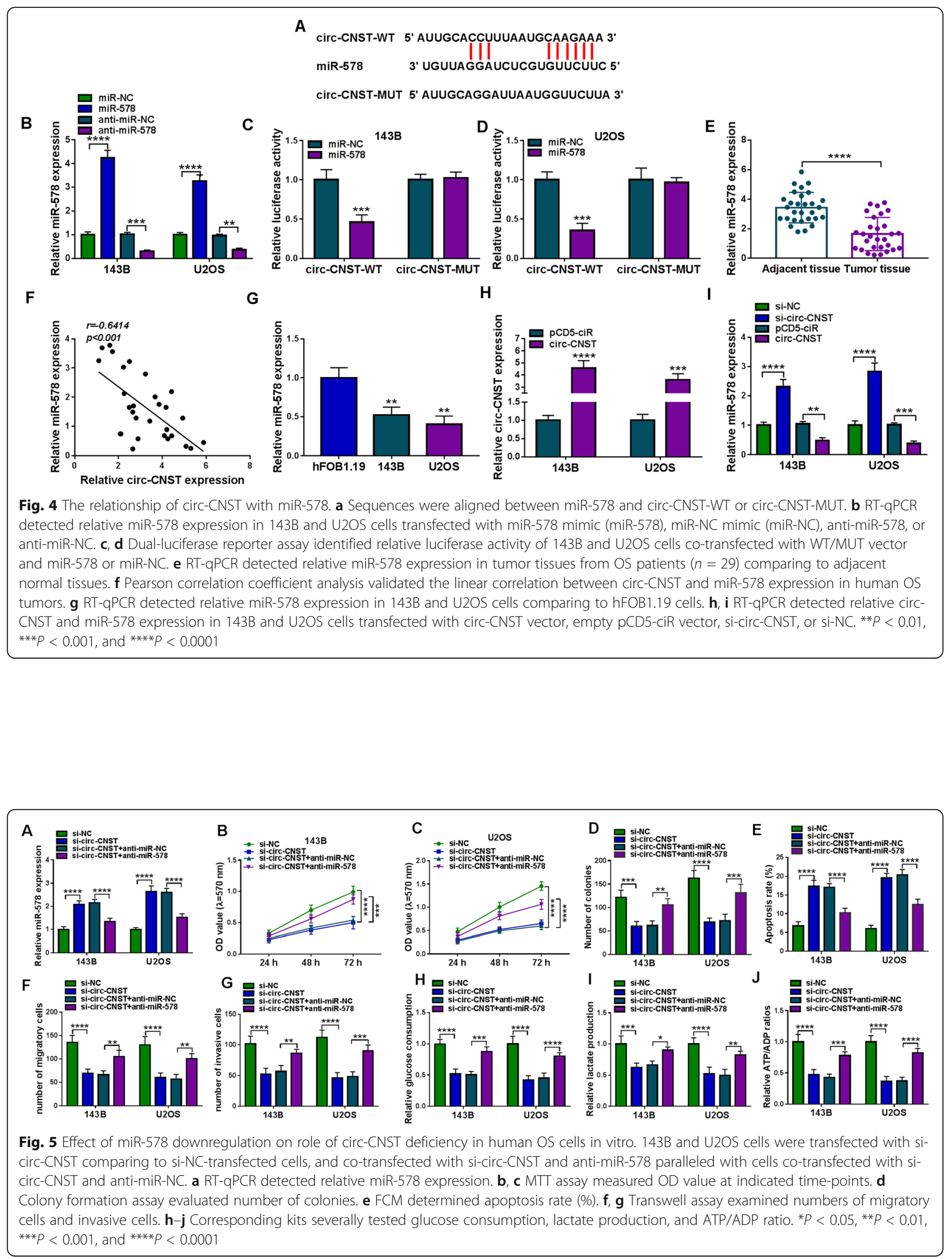
that miR-578 expression was negatively correlated with circ-CNST in OS tumors (Fig. 4f). Besides, low miR-578 was also found in OS tumors from patients with shorter overall survival, advanced TNM stages and lymph node metastasis (Figure S2A-S2C). In $143 \mathrm{~B}$ and U2OS cells, transfection of pCD5-ciR-circCNST (circ-CNST) vector induced ectopic expression of circ-CNST (Fig. 4h), and allied with that was the downregulation of miR-578 (Fig. 4i); contrarily, silencing circ-CNST resulted in miR-578 upregulation (Fig. 4i). These data demonstrated that miR-578 was downregulated in OS patients and cells and was negatively regulated by circ-CNST via target binding.

\section{Downregulating miR-578 counteracted the suppressive} role of circ-CNST deficiency in OS cells in vitro

Anti-miR-578 transfection could lead to depletion of miR-578 in 143B and U2OS cells without and with circ-CNST knockdown (Figs. $4 \mathrm{~b}$ and $5 \mathrm{a}$ ). Furthermore, in circ-CNST-silenced $143 \mathrm{~B}$ and U2OS cells, the inhibited cell proliferation and colony formation were improved with anti-miR-578 transfection, as indicated by higher OD values and colony number (Fig. 5b, d). Additional anti-miR-578 transfection diminished apoptosis rate of $143 \mathrm{~B}$ and U2OS cells expressing si-circ-CNST (Fig. 5e). Silencing circ-CNST depressed the numbers of transwell migratory cells and invasive cells in $143 \mathrm{~B}$ and U2OS cells, and this depression was attenuated by simultaneously depleting miR-578 (Fig. 5f, g). Glycolysis of 143B and U2OS cells was inhibited when circ-CNST was knocked down, which was rescued in the presence of antimiR-578, as evidenced by the increase of glucose consumption, lactate production and ATP/ADP ratio (Fig. 5h-j). These outcomes depicted the counteractive effect of miR-578 downregulation on the suppressive role of circ-CNST knockdown in malignant behaviors and glycolysis of human OS cells in vitro, suggesting a circ-CNST-miR-578 pair in OS.

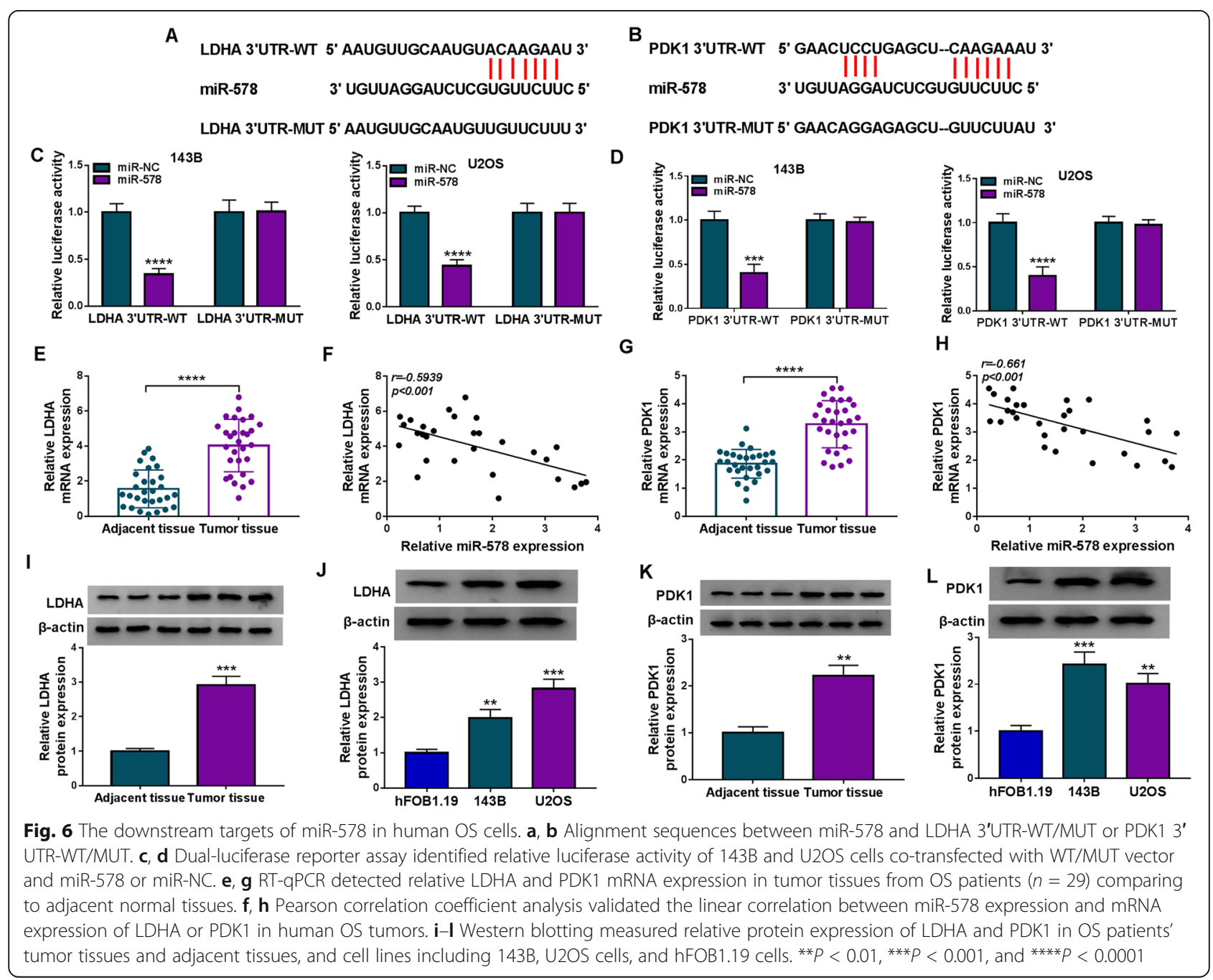


Overexpressing miR-578 suppressed malignant behaviors and glycolysis of OS cells in vitro through inhibiting its target genes, LDHA and PDK1

Targetscan database predicted the potential target genes of miR-578, and glycolysis-related genes were screened. As a results, 3'UTR of LDHA (ENST00000227157.4) and PDK1 (ENST00000282077.3) both showed complementary sequences to miR-578 (Fig. 6a, b). Dualluciferase reporter assay also identified the reduction of luciferase activity in $143 \mathrm{~B}$ and U2OS cells co-transfected with LDHA/PDK1 3'UTR-WT vector and miR-578 mimic (Fig. 6c, d). LDHA and PDK1 mRNAs were highly expressed in OS patients' tumors with negatively linear correlation with miR-578 (Fig. 6e-h). Besides, high LDHA/PDK1 mRNA was found in OS tumors from patients with shorter overall survival, advanced TNM stages, and lymph node metastasis (Figure S3A-S3F). In regarding to protein expression, LDHA and PDK1 levels were higher in three human OS tissues and two OS cell lines (Fig. 6i-1). Expression of LDHA and PDK1 in 143B and U2OS cells was inhibited under miR-578 overexpression condition and was promoted under miR-578 deficiency condition (Figs. 7a and 8a). Notably, LDHA and PDK1 levels in miR-578-overexpressed 143B and U2OS cells could be severally restored by transfecting the recombinant pcDNA plasmids (Figs. $7 \mathrm{~b}$ and $8 \mathrm{~b}$ ). The overexpression of miR-578 inhibited OD values and colony numbers in $143 \mathrm{~B}$ and U2OS cells (Figs. 7c-e and $8 \mathrm{c}-\mathrm{e})$. On the contrary, apoptosis rate of $143 \mathrm{~B}$ and U2OS cells was elevated with miR-578 mimic transfection than miR-NC mimic transfection (Fig. 7f and 8f). Transwell migration and invasion were consistently inhibited in both 143B and U2OS cells after transfection of miR-578 mimic, as evidenced by the declined numbers of migratory cells and invasive cells (Figs. $7 \mathrm{~g}, \mathrm{~h}$ and $8 \mathrm{~g}, \mathrm{~h})$. Glucose consumption, lactate production, and
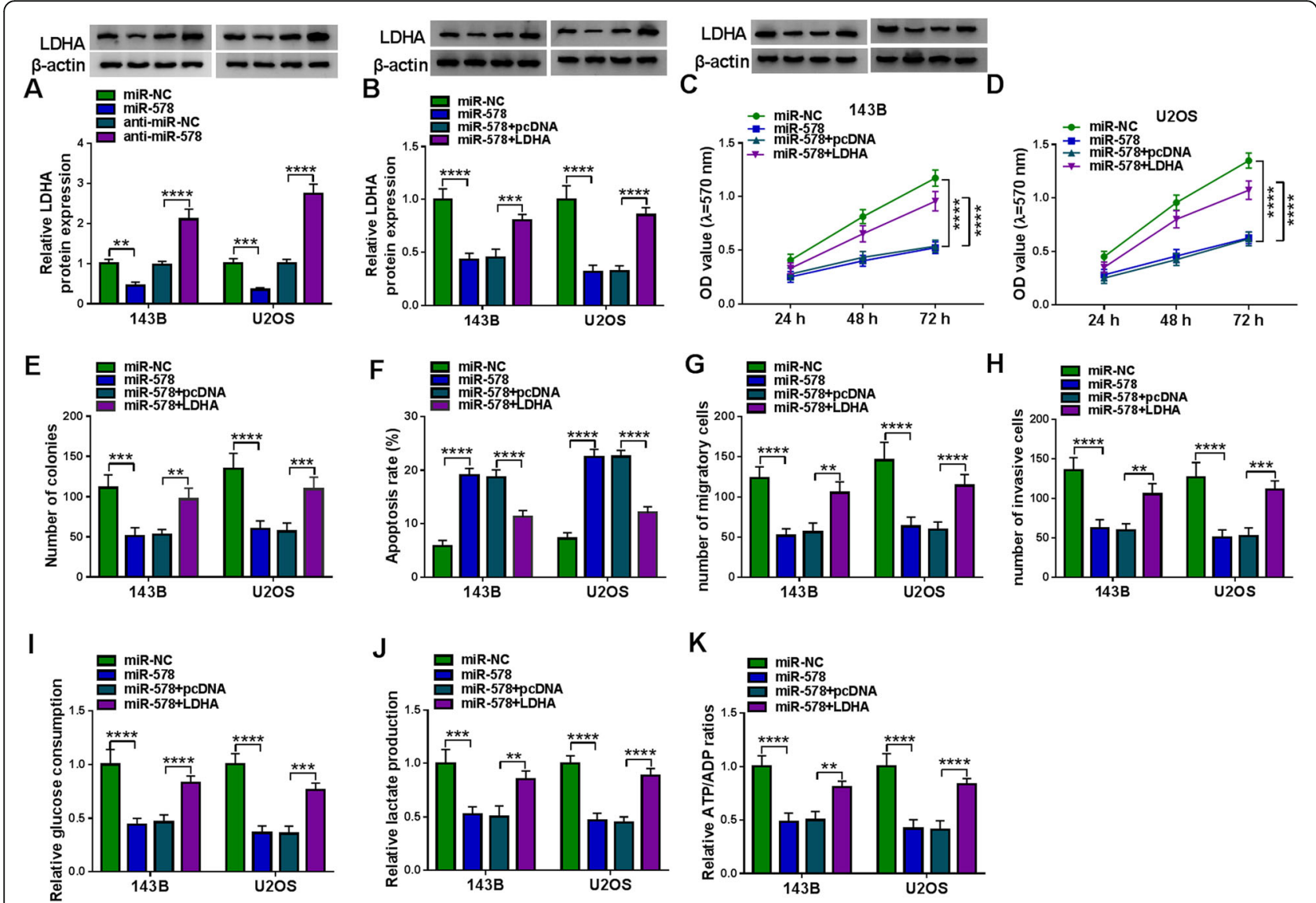

Fig. 7 Mutual effect between miR-578 and LDHA in cell behaviors and glycolysis of OS cells in vitro. a Western blotting detected relative LDHA protein expression in $143 \mathrm{~B}$ and U2OS cells transfected with miR-578, miR-NC, anti-miR-578, or anti-miR-NC. b-k $143 \mathrm{~B}$ and U2OS cells were transfected with miR-578 comparing to miR-NC-transfected cells and co-transfected with miR-578 and pcDNA-LDHA (LDHA) or pCDNA-PDK1 (PDK1) vector paralleled with cells co-transfected with miR-578 and empty pcDNA vector (pcDNA). b Western blotting detected relative LDHA protein expression. c, $\mathbf{d}$ MTT assay measured OD value at indicated time-points. e Colony formation assay evaluated number of colonies. $\mathbf{f}$ FCM determined apoptosis rate (\%). $\mathbf{g}, \mathbf{h}$ Transwell assay examined numbers of migratory cells and invasive cells. $\mathbf{i}-\mathbf{k}$ Corresponding kits severally tested glucose consumption, lactate production, and ATP/ADP ratio. ${ }^{*} P<0.05$, ${ }^{* *} P<0.01$, ${ }^{* *} P<0.001$, and ${ }^{* * *} P<0.0001$ 


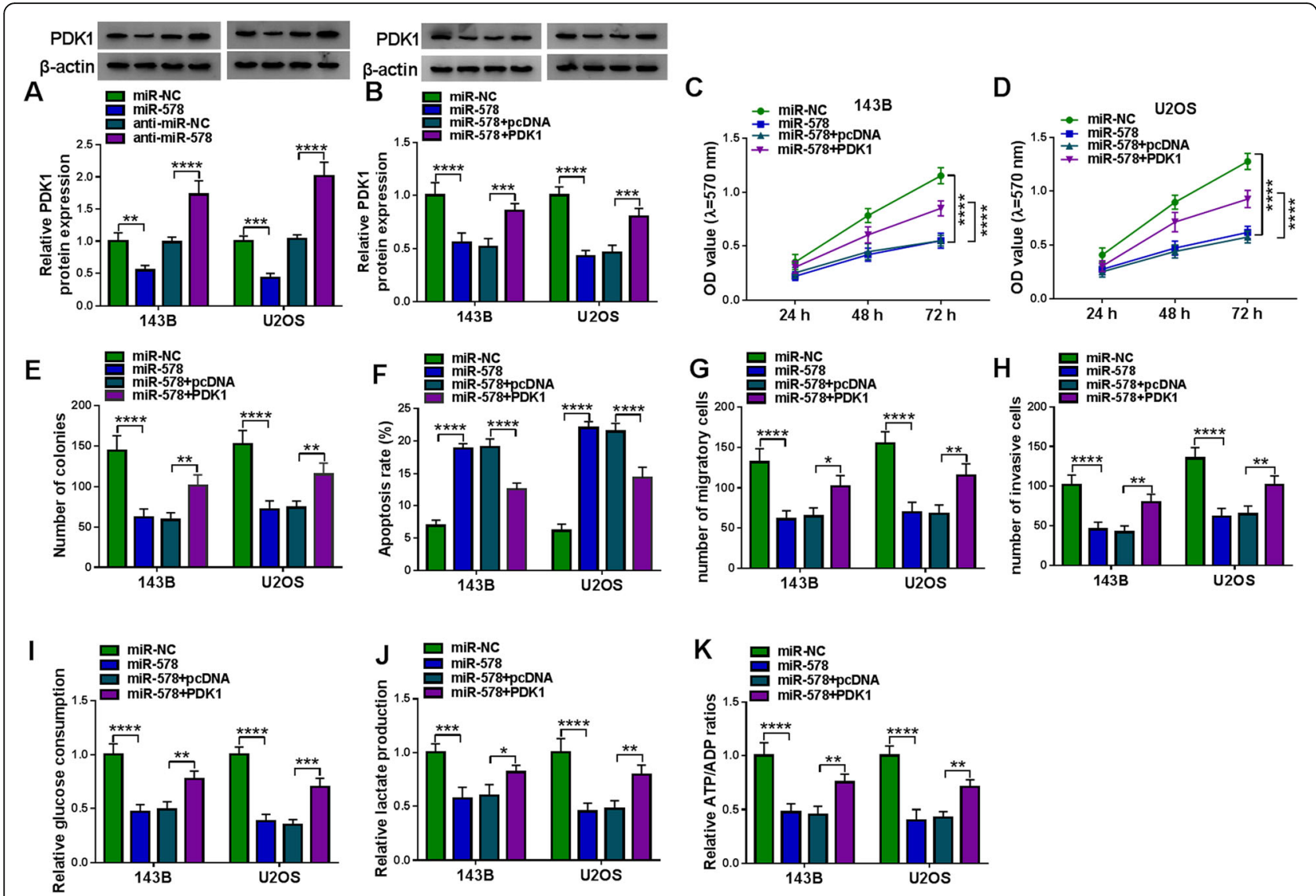

Fig. 8 Mutual effect between miR-578 and PDK1 in cell behaviors and glycolysis of OS cells in vitro. a Western blotting detected relative PDK1 protein expression in 143B and U2OS cells transfected with miR-578, miR-NC, anti-miR-578, or anti-miR-NC. b-k 143B and U2OS cells were transfected with miR-578 comparing to miR-NC-transfected cells, and co-transfected with miR-578 and pcDNA-PDK1 (PDK1) vector paralleled with cells co-transfected with miR-578 and pcDNA. b Western blotting detected relative PDK1 protein expression. $\mathbf{c}$, $\mathbf{d}$ MTT assay measured OD value at indicated time-points. e Colony formation assay evaluated number of colonies. f FCM determined apoptosis rate (\%). $\mathbf{g}, \mathbf{h}$ Transwell assay examined numbers of migratory cells and invasive cells. i-k Corresponding kits severally tested glucose consumption, lactate production, and ATP/ADP ratio. ${ }^{*} P<0.05,{ }^{* *} P<0.01,{ }^{* *} P<0.001$, and ${ }^{* * *} P<0.0001$

ATP/ADP ratio were overall decreased in miR-578upregulated 143B and U2OS cells (Figs. 7i-k and 8i-k). These results demonstrated a tumor-suppressive role of miR-578 in cell proliferation, colony formation, apoptosis, migration, invasion, and glycolysis of human OS cells in vitro, whereas this tumor suppression was partially reversed by ectopic expression of LDHA or PDK1 (Figs. $7 \mathrm{c}-\mathrm{k}$ and $8 \mathrm{c}-\mathrm{k}$ ). These outcomes suggested a miR578-LDHA/PDK1 pair in OS.

\section{Circ-CNST could regulate LDHA and PDK1 expression via sponging miR-578}

In mechanism, LDHA could be modulated and downregulated by circ-CNST knockdown, and this downregulation was canceled by simultaneously silencing miR-578 (Fig. 9a). Similar to LDHA expression, PDK1 expression could be positively regulated by circ-CNST via miR-578 (Fig. 9b). These outcomes proposed a circ-CNST-miR578-LDHA/PDK1 ceRNA regulatory network.

\section{Discussion}

Expression profiles of circRNAs had been obtained in human OS tissues [21], as well as OS cell lines [22, 23]. Through analyzing the GSE96964 microarray, several circRNAs had been found to be highly expressed in OS patients' tumors, such as circ-0000285, circ-XPR1, and circ-0000073 [24-26], as well as circ-CNST [12]. Wang et al. [12] proposed that circ-CNST promoted proliferation and colony formation of OS cells (SW-1353, MG63, HOS, and U-2OS), and was correlated with tumor size $(\geq 5 \mathrm{~cm})$ and shorter survival. Here, except for the inhibitory effect on proliferation and colony formation, we also noticed that circ-CNST knockdown exerted promoting effect on apoptosis and suppressive effect on migration, invasion, and glycolysis in OS cells in vitro. Moreover, growth of OS cells in vivo was retarded by silencing circ-CNST. High circ-CNST expression might predict not only larger tumor size and shorter survival, but also lymph node metastasis in OS patients. 

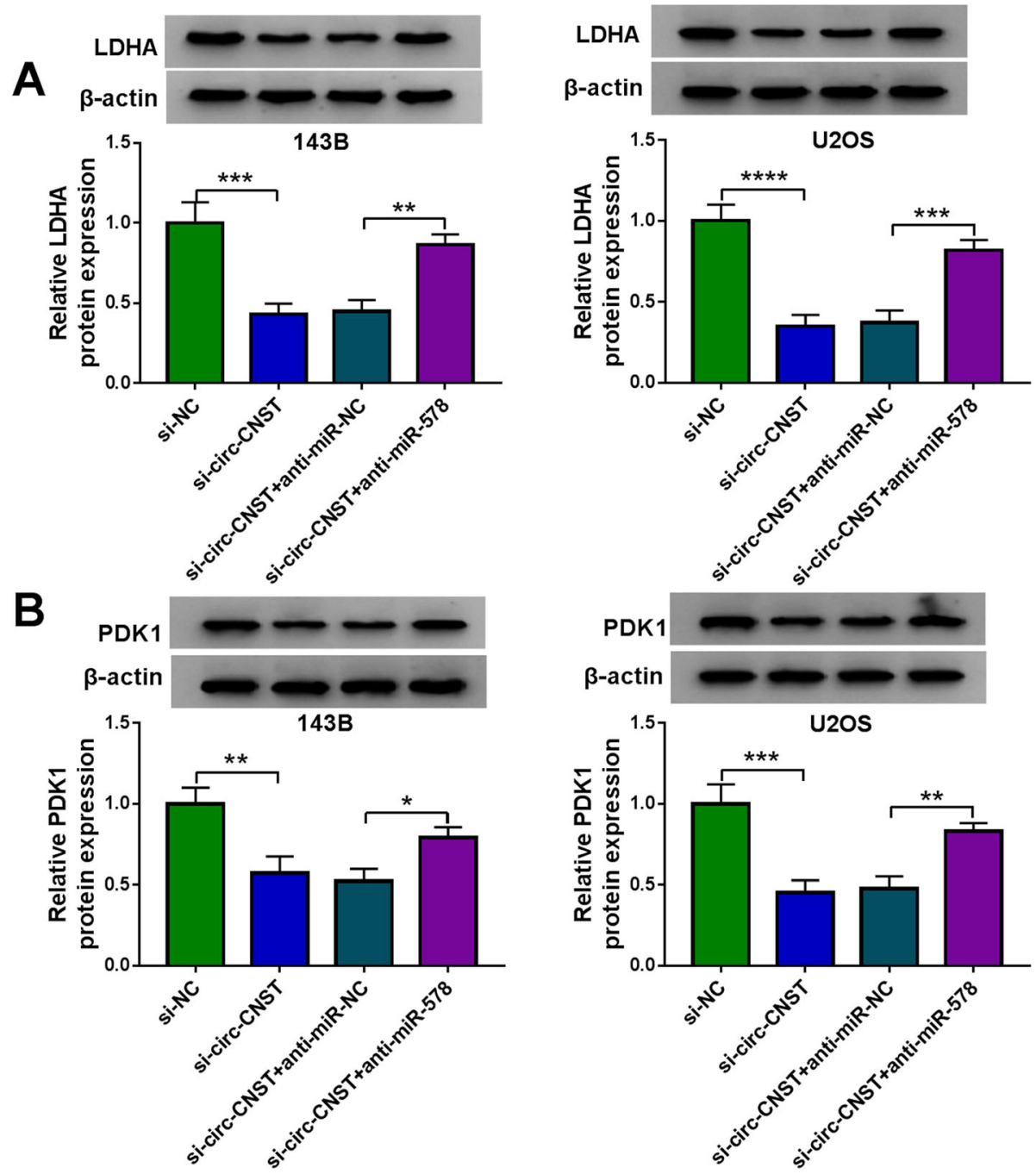

Fig. 9 The regulatory effect among circ-CNST, miR-578, and LDHA or PDK1. a-d Western blotting testified relative LDHA and PDK1 protein expression in 143B and U2OS cells transfected with si-NC or si-circ-CNST, and co-transfected with si-circ-CNST and anti-miR-NC or anti-miR-578. ${ }^{*} P$ $<0.05,{ }^{* *} P<0.01,{ }^{* * *} P<0.001$, and ${ }^{* * *} P<0.0001$

Therewith, this study enhanced the understanding of circ-CNST expression and role in OS. By the way, circCNST was a cytoplasmic circRNA in OS cells which was resistant to RNase $\mathrm{R}$ digestion. Another report also claimed the stability of circ-CNST with actinomycin D treatment [12].

In this study, circ-CNST acted as miR-578 sponge to sequester and inhibit miR-578 expression and activity. Expression of miR-578 was downregulated in OS patients and cells, and abnormal upregulation of miR-578 could inhibit the proliferation and migration of OS cells, which was consistent with previous data [21]. Besides, colony formation, invasion, and glycolysis were observed in this study to be depressed by elevating miR-578 in OS cells, accompanied with apoptosis promotion. Above cell functions of miR-578 in OS cells were similar to that in breast cancer cells [27]. By the way, miR-578 was probably firstly documented to be potential player in BRCAmutated breast cancer and was associated with VEGF and HIF1 signaling pathways [28]. VEGF and HIF1A were targeted and regulated by miR-578 in regulation of tumor progression $[21,27]$. LDHA and PDK1 were key enzymes involved in HIF1 signaling pathway and glycolysis. HIF1A could bind to LDHA, and blocking HIF1A attenuated LDHA expression even under hypoxia [29]. Ku80 was a potential molecular target for melanoma treatment and regulated anti-tumor role of melatonin by targeting and activating PDK1 in HIF1Adependent manner [30]. Here, we identified LDHA and PDK1 as novel target genes of miR-578 in OS. Both of them drove glycolysis in OS cells to facilitate tumor maintenance partially through miRNAs regulation [31- 
34]. Our results suggested miR-578 as a novel glycolysisrelated miRNA in OS.

Overexpression of LDHA and PDK were observed in several tumors and were frequently associated with chemotherapy-related drug resistance, invasion and metastasis $[14,35,36]$. LDHA was an important part of the final step of the glycolytic pathway, and PDK1 was a gatekeeper enzyme involved in altered glucose metabolism towards glycolysis. Here, we found that expression of LDHA and PDK1 was upregulated in OS tissues and cells, which supported the existing studies [31, 34]. Inhibiting endogenous LDHA and LDHA inhibitors could significantly suppress glycolysis, cell proliferation, and invasion but induce apoptosis of OS cells [15, 32, 37]. Li et al. stated that restoration of PDK1 enhanced proliferative and invasive abilities in OS cells [34]. In addition, colony formation, migration, and glycolysis could also been augmented by overexpressing PDK1, as indicated in this study.

\section{Conclusion}

In conclusion, we demonstrated that silencing circCNST could suppress malignant behaviors and glycolysis of OS cells by regulating LDHA and PDK1 via sponging miR-578, suggesting a circ-CNST-miR-578-LDHA/ PDK1 ceRNA network in OS. This study enhanced the understanding of circ-CNST role in OS progression and indicated circ-CNST as a potential therapeutic target for OS.

\begin{abstract}
Abbreviations
OS: Osteosarcoma; LDHA: Lactate dehydrogenase A; PDK1: Pyruvate dehydrogenase kinase 1; ATP/ADP: Adenosine triphosphate/adenosine diphosphate; GEO: Gene Expression Omnibus; circ-CNST: Circular RNA CNST; ceRNA: Competing endogenous RNA; RT-qPCR: Quantitative real-time polymerase chain reaction; RNase R: Ribonuclease R; CDNA: Complementary DNA; siRNA: Small interference RNA; si-circ-CNST: siRNA targeting circ-CNST; antimiR-578: miR-578 inhibitor; MTT: 3-(4,5-Dimethylthiazolyl-2)-2,5diphenyltetrazolium bromide; FCM: Flow cytometry; FITC/PI: Fluorescein isothiocyanate/propidium iodide
\end{abstract}

\section{Supplementary Information}

The online version contains supplementary material available at https://doi. org/10.1186/s13018-021-02427-0.

Additional file 1 : Figure S1. The association between circ-CNST expression and clinical features. (A) Kaplan-Meier survival analysis determined overall survival of 29 OS patients with low expression of circ-CNST $(n=14)$ and high expression of circ-CNST ( $n=15)$. (B, C) RT-qPCR compared relative circ-CNST expression in I-II stage tumors $(n=12)$ and III-IV stage tumors ( $n=17$ ), tumors from OS patients with lymph node metastasis ( $n=$ 18) and patients without that $(n=11)$. ${ }^{* * *} P<0.0001$.

Additional file $\mathbf{2}$ :Figure S2. The association between miR-578 expression and clinical features. (A) Kaplan-Meier survival analysis determined overall survival of 29 OS patients with low expression of miR-578 $(n=15)$ and high expression of miR-578 ( $n=14)$. (B, C) RT-qPCR compared relative miR-578 expression in I-II stage tumors ( $n=12)$ and III-IV stage tumors ( $n=$ 17), tumors from OS patients with lymph node metastasis $(n=18)$ and patients without that $(n=11)$. ${ }^{* * * *} P<0.0001$.
Additional file $\mathbf{3}$ :Figure S3. The association between LDHA/PDK1 expression and clinical features. (A, D) Kaplan-Meier survival analysis determined overall survival of 29 OS patients with low expression of LDHA $(n=14)$, high expression of LDHA $(n=15)$, low expression of PDK1 $(n=14)$, high expression of PDK1 ( $n=15)$. RT-qPCR compared relative LDHA mRNA and PDK1 mRNA expression in $(B, E) I-I I$ stage tumors $(n=12)$ and III-IV stage tumors $(n=17)$, and $(C, F)$ tumors from OS patients with lymph node metastasis $(n=18)$ and patients without that $(n=11)$. ${ }^{* * *} P<0.0001$.

\section{Acknowledgements}

None

\section{Authors' contributions}

$\mathrm{RH}$ conceived and designed the experiments, performed the experiments and analyzed and interpreted the data, and wrote the paper. SC analyzed interpreted the data and performed the experiments. JY performed the experiments and analyzed the data. The authors read and approved the final manuscript.

\section{Funding}

The authors declare no conflict of interest, financial or otherwise.

Availability of data and materials

All data generated or analyzed during this study are included in this article.

\section{Declarations}

\section{Ethics approval and consent to participate}

The design of this protocol follows the tenets of the Declaration of Helsinki, approved by the Ethics Committee of The Central Hospital of Enshi Tujia and Miao Autonomous Prefecture.

\section{Consent for publication}

Written informed consents were obtained from all participants.

\section{Competing interests}

The authors declare that they have no competing interest.

\section{Author details}

${ }^{1}$ Department of Spine Surgery Clinic, The Central Hospital of Enshi Tujia and Miao Autonomous Prefecture, Enshi City, Hubei Province, China.

${ }^{2}$ Department of Oncology, The Central Hospital of Enshi Tujia and Miao Autonomous Prefecture, Enshi City, Hubei Province, China. ${ }^{3}$ Department of Joint Surgery, The Central Hospital of Enshi Tujia and Miao Autonomous Prefecture, No. 158 Wuyang Avenue, Enshi City 445000, Hubei Province, China.

Received: 18 November 2020 Accepted: 14 April 2021

Published online: 07 May 2021

\section{References}

1. Kansara M, Teng MW, Smyth MJ, Thomas DM. Translational biology of osteosarcoma. Nat Rev Cancer. 2014;14(11):722-35. https://doi.org/10.1038/ $\operatorname{nrc3838.}$

2. Giang AH, Raymond T, Brookes P, de Mesy BK, Schwarz E, et al. Mitochondrial dysfunction and permeability transition in osteosarcoma cells showing the Warburg effect. J Biol Chem. 2013;288(46):33303-11. https:// doi.org/10.1074/jbc.M113.507129.

3. Han T, Kang D, Ji D, Wang X, Zhan W, et al. How does cancer cell metabolism affect tumor migration and invasion? Cell Adhes Migr. 2013; 7(5):395-403. https://doi.org/10.4161/cam.26345.

4. Chen X, Chen S, Yu D. Metabolic reprogramming of chemoresistant cancer cells and the potential significance of metabolic regulation in the reversal of cancer chemoresistance. Metabolites. 2020;10(7).

5. Harmon C, O'Farrelly C, Robinson MW. The immune consequences of lactate in the tumor microenvironment. Adv Exp Med Biol. 2020;1259:11324. https://doi.org/10.1007/978-3-030-43093-1_7.

6. Pereira-Nunes A, Afonso J, Granja S, Baltazar F. Lactate and lactate transporters as key players in the maintenance of the Warburg effect. Adv 
Exp Med Biol. 2020;1219:51-74. https://doi.org/10.1007/978-3-030-3402 5-4_3.

7. Bielack SS, Smeland S, Whelan JS, Marina N, Jovic G, Hook JM, et al. Methotrexate, doxorubicin, and cisplatin (MAP) plus maintenance pegylated interferon alfa- $2 \mathrm{~b}$ versus MAP alone in patients with resectable high-grade osteosarcoma and good histologic response to preoperative MAP: first results of the EURAMOS-1 good response randomized controlled trial. J Clin Oncol. 2015;33(20):2279-87. https://doi.org/10.1200/JCO.2014.60.0734.

8. Wang C, Jing J, Cheng L. Emerging roles of non-coding RNAs in the pathogenesis, diagnosis and prognosis of osteosarcoma. Investig New Drugs. 2018;36(6):1116-32. https://doi.org/10.1007/s10637-018-0624-7.

9. Soghli N, Qujeq D, Yousefi T, Soghli N. The regulatory functions of circular RNAs in osteosarcoma. Genomics. 2020;112(4):2845-56. https://doi.org/10.1 016/j.ygeno.2020.03.024.

10. Tu C, He J, Qi L, Ren X, Zhang C, Duan Z, et al. Emerging landscape of circular RNAs as biomarkers and pivotal regulators in osteosarcoma. J Cell Physiol. 2020;235(12):9037-58. https://doi.org/10.1002/jcp.29754.

11. Wan B, Hu H, Wang R, Liu W, Chen D. Therapeutic potential of circular RNAs in osteosarcoma. Front Oncol. 2020;10:370. https://doi.org/10.3389/fonc.202 0.00370

12. Wang JH, Wu XJ, Duan YZ, Li F. Circular RNA_CNST promotes the tumorigenesis of osteosarcoma cells by sponging miR-421. Cell Transplant. 2020;29:963689720926147.

13. Feng Y, Xiong Y, Qiao T, Li X, Jia L, Han Y. Lactate dehydrogenase a: a key player in carcinogenesis and potential target in cancer therapy. Cancer Med. 2018;7(12):6124-36. https://doi.org/10.1002/cam4.1820.

14. Sradhanjali S, Reddy MM. Inhibition of pyruvate fehydrogenase kinase as a therapeutic strategy against cancer. Curr Top Med Chem. 2018;18(6):444-53. https://doi.org/10.2174/1568026618666180523105756.

15. Gao S, Tu DN, Li H, Jiang JX, Cao X, You JB, et al. Pharmacological or genetic inhibition of LDHA reverses tumor progression of pediatric osteosarcoma. Biomed Pharmacother. 2016;81:388-93. https://doi.org/10.101 6/j.biopha.2016.04.029.

16. Cao W, Wang Z, Han X, Liu J, Wang W. In vitro cytotoxicity screening to identify novel anti-osteosarcoma therapeutics targeting pyruvate dehydrogenase kinase 2. Bioorg Med Chem Lett. 2019;29(20):126665. https://doi.org/10.1016/j.bmcl.2019.126665.

17. Wang $D$, Yang $S$, Wang $H$, Wang J, Zhang $Q$, Zhou $S$, et al. The progress of circular RNAs in various tumors. Am J Transl Res. 2018;10(6):1571-82.

18. Qiu Y, Pu C, Li Y, Qi B. Construction of a circRNA-miRNA-mRNA network based on competitive endogenous RNA reveals the function of circRNAs in osteosarcoma. Cancer Cell Int. 2020;20(1):48. https://doi.org/10.1186/s12935020-1134-1.

19. Xiong W, Zhang Y, Yu H. Comprehensive characterization of circular RNAs in osteosarcoma cell lines. Cell Signal. 2020;71:109603. https://doi.org/10.1016/j. cellsig.2020.109603.

20. Wu Y, Xie Z, Chen J, Chen J, Ni W, Ma Y, et al. Circular RNA circTADA2A promotes osteosarcoma progression and metastasis by sponging miR-203a3p and regulating CREB3 expression. Mol Cancer. 2019;18(1):73. https://doi. org/10.1186/s12943-019-1007-1.

21. Ji X, Shan L, Shen P, He M. Circular RNA circ 001621 promotes osteosarcoma cells proliferation and migration by sponging miR-578 and regulating VEGF expression. Cell Death Dis. 2020;1 1(1):18. https://doi.org/1 0.1038/s41419-019-2204-y.

22. Xu Y, Yao T, Huang K, Liu G, Huang Y, Gao J, et al. Circular RNA circTUBGCP3 is up-regulated and promotes cell proliferation, migration and survivability via sponge mir-30b in osteosarcoma. Onco Targets Ther. 2020; 13:3729-37. https://doi.org/10.2147/OTT.S245366.

23. Li S, Zeng M, Yang L, Tan J, Yang J, Guan H, et al. Hsa_circ_0008934 promotes the proliferation and migration of osteosarcoma cells by targeting miR-145-5p to enhance E2F3 expression. Int J Biochem Cell Biol. 2020;127:105826. https://doi.org/10.1016/j.biocel.2020.105826.

24. Zhang Z, Pu F, Wang B, Wu Q, Liu J, Shao Z. Hsa_circ_0000285 functions as a competitive endogenous RNA to promote osteosarcoma progression by sponging hsa-miRNA-599. Gene Ther. 2020;27(5):186-95. https://doi.org/10.1 038/s41434-019-0112-5.

25. Mao X, Guo S, Gao L, Li G. Circ-XPR1 promotes osteosarcoma proliferation through regulating the miR-214-5p/DDX5 axis. Hum Cell. 2020.

26. Li X, Liu Y, Zhang X, Shen J, Xu R, Liu Y, et al. Circular RNA hsa_circ_ 0000073 contributes to osteosarcoma cell proliferation, migration, invasion and methotrexate resistance by sponging miR-145-5p and miR-151-3p and upregulating NRAS. Aging (Albany NY). 2020;12(14):14157-73. https://doi. org/10.18632/aging.103423.

27. Chen Z, Wang F, Xiong Y, Wang N, Gu Y, Qiu X. CircZFR functions as a sponge of miR-578 to promote breast cancer progression by regulating HIF1A expression. Cancer Cell Int. 2020;20(1):400. https://doi.org/10.1186/s12 935-020-01492-5.

28. Danza K, De Summa S, Pinto R, Pilato B, Palumbo O, et al. MiR-578 and miR573 as potential players in BRCA-related breast cancer angiogenesis. Oncotarget. 2015;6(1):471-83. https://doi.org/10.18632/oncotarget.2509.

29. Cui XG, Han ZT, He SH, Wu XD, Chen TR, Shao CH, et al. HIF1/2alpha mediates hypoxia-induced LDHA expression in human pancreatic cancer cells. Oncotarget. 2017;8(15):24840-52. https://doi.org/10.18632/oncotarget.1 5266.

30. Liu T, Jin L, Chen M, Zheng Z, Lu W, Fan W, et al. Ku80 promotes melanoma growth and regulates antitumor effect of melatonin by targeting HIF1-alpha dependent PDK-1 signaling pathway. Redox Biol. 2019;25:101197. https:// doi.org/10.1016/.jedox.2019.101197.

31. Chen H, Gao S, Cheng C. MiR-323a-3p suppressed the glycolysis of osteosarcoma via targeting LDHA. Hum Cell. 2018;31(4):300-9. https://doi. org/10.1007/s13577-018-0215-0.

32. Zheng $\mathrm{XM}, \mathrm{Xu} \mathrm{CW}$, Wang F. MiR-33b inhibits osteosarcoma cell proliferation through suppression of glycolysis by targeting lactate dehydrogenase a (LDHA). Cell Mol Biol (Noisy-le-grand). 2018;64(11):31-5. https://doi.org/10.14 715/cmb/2018.64.11.6.

33. Du JY, Wang LF, Wang Q, Yu LD. miR-26b inhibits proliferation, migration, invasion and apoptosis induction via the downregulation of 6phosphofructo-2-kinase/fructose-2,6-bisphosphatase-3 driven glycolysis in osteosarcoma cells. Oncol Rep. 2015;33(4):1890-8. https://doi.org/10.3892/ or.2015.3797.

34. Li Z, Shen J, Chan MT, Wu WK. MicroRNA-379 suppresses osteosarcoma progression by targeting PDK1. J Cell Mol Med. 2017;21(2):315-23. https:// doi.org/10.1111/jcmm.12966

35. Emmanouilidi A, Falasca M. Targeting PDK1 for chemosensitization of cancer cells. Cancers (Basel). 2017;9(10).

36. Jin L, Chun J, Pan C, Alesi GN, Li D, Magliocca KR, et al. Phosphorylationmediated activation of LDHA promotes cancer cell invasion and tumour metastasis. Oncogene. 2017;36(27):3797-806. https://doi.org/10.1038/onc.2 017.6

37. Fang $A$, Zhang $Q$, Fan $H$, Zhou Y, Yao $Y$, Zhang $Y$, et al. Discovery of human lactate dehydrogenase a (LDHA) inhibitors as anticancer agents to inhibit the proliferation of MG-63 osteosarcoma cells. Medchemcomm. 2017;8(8): 1720-6. https://doi.org/10.1039/C7MD00222J.

\section{Publisher's Note}

Springer Nature remains neutral with regard to jurisdictional claims in published maps and institutional affiliations.

Ready to submit your research? Choose BMC and benefit from:

- fast, convenient online submission

- thorough peer review by experienced researchers in your field

- rapid publication on acceptance

- support for research data, including large and complex data types

- gold Open Access which fosters wider collaboration and increased citations

- maximum visibility for your research: over $100 \mathrm{M}$ website views per year

At BMC, research is always in progress.

Learn more biomedcentral.com/submissions 